\title{
Bénin: Target men to increase use of health services
}

Frontiers in Reproductive Health

Follow this and additional works at: https://knowledgecommons.popcouncil.org/departments_sbsr-rh

Part of the Community-Based Research Commons, Demography, Population, and Ecology Commons, Family, Life Course, and Society Commons, International Public Health Commons, and the Medicine and Health Commons How does access to this work benefit you? Let us know!

\section{Recommended Citation}

"Bénin: Target men to increase use of health services," FRONTIERS OR Summary. Washington, DC:

Population Council, 2001. 


\section{Bénin Access}

OR Summary 18

\section{Target Men to Increase Use of Health Services}

\begin{abstract}
In rural Bénin men control household resources and make most decisions regarding childbearing and use of health services. Programs to improve maternal and child health should educate community members on the need to invest in health care and seek prompt treatment for illness. Reproductive health programs should also educate men about family planning and address women's concerns about contraceptive side effects.
\end{abstract}

\section{Background}

After initiating health sector reforms in 1994, the Bénin government established the Integrated Family Health Project, known locally as PROSAF. Funded by the U.S. Agency for International Development, PROSAF operates in the Borgou region, which is mostly rural and has the country's most severe health problems.

PROSAF managers wanted to understand why local people were not using health services, despite their poor health. They requested the African Population and Health Research Centre (APHRC) to study the way that households and communities in the Borgou make decisions on health care. In a study conducted from May to December 2000 with support from the Population Council, APHRC sought to identify sociocultural factors that might impede access to health care in the region and to recommend approaches to overcome these obstacles.

For this qualitative study, researchers conducted 108 in-depth interviews and 36 focus group discussions in five districts of the Borgou. The study used a representative sample of the region's population stratified by ethnic group, gender, and age (15-24 years, 2549, and 50 and older). In each district researchers interviewed a district medical officer, a nurse, a midwife, a traditional healer, and a community agent.

\section{Findings}

- Three major factors affect access to and utilization of health care and family planning services:

\& In allocating household resources, agriculture, housing, and ceremonial functions such as funerals and weddings take priority. Payments for health care depend on available funds and timing of the illness.

$\rightarrow$ Adult men make unilateral decisions in household resource allocation and health care.

"My money and myself, we are under my husband's control."

(married woman, age 48)

$\nLeftarrow$ People prefer alternative health care, mainly traditional healers or self-medication, because of their low cost. Perceptions of the cause of illness - such as the idea that using amulets can cure fevers or prevent infections, including sexually transmitted infections- 
also affect the type of health services sought. Use of modern medicine tends to occur as a last resort, and only when symptoms are advanced.

\section{"When the weather is very hot, that causes gonorrhea. When you eat plenty of mangos you can also get gonorrhea." (unmarried youth, age 21)}

- If people use modern facilities, quality of care is the most important concern. Clients will pay higher fees and travel further to receive better care. Community members cited a shortage of supplies and medications as well as absenteeism, lack of training, poor treatment of patients, and black-marketing of drugs by providers as reasons for relying on alternative health care sources.

- Many people have heard of modern contraceptive methods, especially the injectable, the pill, and the IUD. Both men and women saw FP as a way of spacing births with such benefits as rest for the mother, better care for the child, and fewer economic strains for the family. They also viewed it as a substitute for sexual abstinence, the traditional method of spacing births. Male participants understood that condoms can prevent pregnancy as well as HIV/ AIDS, but they mainly use condoms for extramarital sex.

- Few women use modern contraception, since they are worried about side effects. For example, some women believe that contraceptive use causes sterility. Husbands' disapproval also limits use, as men make decisions regarding fertility. Many women believe that providers require their husband's consent for contraceptives, although some women obtain methods secretly.
- Communication about FP is limited, both between husbands and wives and between parents and children. Adolescents said that shame is a major factor in this lack of communication. Both adolescents and adults associate FP use with promiscuity and infidelity. Women said that discussing FP with their husbands could lead to family discord, violence, or divorce. They expressed an urgent need to provide FP information to husbands.

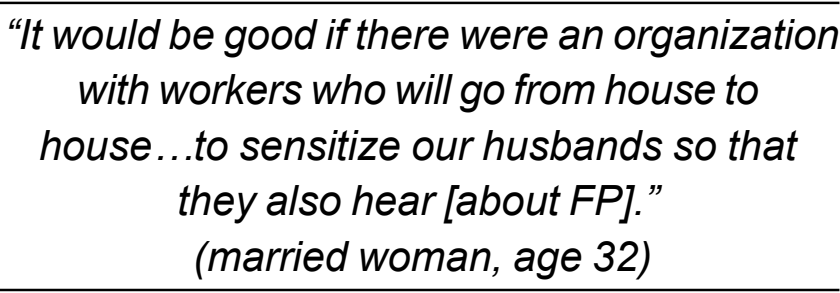

\section{Policy Implications}

- Programs seeking to increase use of modern health care services, including FP, must involve men. Use of properly trained community agents could be an effective way of changing men's attitudes about FP.

- Community outreach programs should seek to increase awareness of the need to seek treatment for illness as soon as it occurs. Drug prices should be standardized, and price information should be posted in all health facilities and provided to the community.

- Providers should receive training to improve or update their skills, particularly interpersonal skills. Supervisors should receive training to improve staff supervision, prevent absenteeism, and strengthen management of drug supplies.

May 2001

\footnotetext{
Ngom, Pierre et al. 2000. Intra-Household Decision-Making on Health and Resource Allocation in the Borgou, Bénin: Final Report. For more information, contact: African Population and Health Research Center, P.O. Box 17643, Nairobi, Kenya. Tel.: 254-2-713 480; Fax: 2542-713 479; E-mail: aphrc@popcouncil.orke.
}

This project was conducted with support from the U.S. AGENCY FOR INTERNATIONAL DEVELOPMENT under Cooperative Agreement Number HRN-A-00-98-00012-00. 